\title{
Comparing responsiveness of the EQ-5D-5L, EQ-5D-3L and EQ VAS in stroke patients
}

\author{
Dominik Golicki • Maciej Niewada • \\ Anna Karlińska · Julia Buczek • Adam Kobayashi • \\ M. F. Janssen • A. Simon Pickard
}

Accepted: 19 November 2014/Published online: 26 November 2014

(C) The Author(s) 2014. This article is published with open access at Springerlink.com

\begin{abstract}
Aims To date, evidence to support the construct validity of the EQ-5D-5L has primarily focused on cross-sectional data. The aims of this study were to examine the responsiveness of EQ-5D-5L in patients with stroke and to compare it with responsiveness of EQ-5D-3L and visual analogue scale (EQ VAS).

Methods We performed an observational longitudinal cohort study of patients with stroke. At 1 week and 4 months
\end{abstract}

D. Golicki $(\bowtie) \cdot$ M. Niewada

Department of Experimental and Clinical Pharmacology,

Medical University of Warsaw, Banacha 1B St., 02-097 Warsaw,

Poland

e-mail: dominik.golicki@gmail.com

M. Niewada

e-mail: maciej.niewada@wum.edu.pl

A. Karlińska · J. Buczek · A. Kobayashi

2nd Department of Neurology, Institute of Psychiatry and

Neurology, Jana III Sobieskiego 9 St, 02-957 Warsaw, Poland

e-mail: akarlinska@ipin.edu.pl

J. Buczek

e-mail: jbuczek@ipin.edu.pl

A. Kobayashi

e-mail: akobayas@ipin.edu.pl

M. F. Janssen

Department of Medical Psychology and Psychotherapy, Erasmus

MC, Erasmus University, PO Box 2040, 3000, CA, Rotterdam,

The Netherlands

e-mail: mf.bas.janssen@gmail.com

\section{A. S. Pickard}

Department of Pharmacy Systems, Outcomes, and Policy,

College of Pharmacy, University of Illinois at Chicago, 833

South Wood St, Chicago, IL MC886, USA

e-mail: pickard1@uic.edu post-stroke, patients were assessed with modified Rankin Scale (mRS) and Barthel Index (BI) and were administered the EQ-5D-5L and EQ-5D-3L, including the EQ VAS. The EQ-5D-5L index scores were derived using the crosswalk methodology developed by the EuroQol Group. We classified patients according to two external criteria, based on mRS or BI, into 3 categories: 'improvement,' 'stable' or 'deterioration'. We assessed the responsiveness of each measure in each patient subgroup using: effect size (ES), standardized response mean (SRM), $F$-statistic, relative efficiency and area under the receiver operating characteristic curve.

Results A total of 112 patients (52\% females; mean age 70.6 years; $93 \%$ ischemic stroke) completed all the instruments at both occasions. In subjects with clinical improvement, EQ-5D-5L was consistently responsive, showing moderate ES (0.51-0.71) and moderate to large SRM (0.69-0.86). In general, EQ-5D-3L index appeared to be more responsive (ES 0.63-0.82; SRM 0.77-1.06) and EQ VAS less responsive (ES 0.51-0.65; SRM 0.59-0.69) than EQ-5D-5L index.

Conclusions The EQ-5D-5L index, based on the crosswalk value set, seems to be appropriately responsive in patients with stroke, 4 months after disease onset. As far as EQ-5D-5L index is scored according to crosswalk approach, the EQ-5D-3L index appears to be more responsive in stroke population.

Keywords EQ-5D-5L $\cdot$ EQ-5D-3L $\cdot$ Health-related quality of life · Patient-reported outcomes · Psychometrics · Stroke

\section{Introduction}

The EQ-5D is a standardized preference-based measure of health that provides a simple, generic measure for clinical 
and economic assessment [1, 2]. Its classical, three-level version (now called EQ-5D-3L) is successfully used as a secondary outcome in contemporary stroke trials [3]. A 5-level version of the EQ-5D (EQ-5D-5L) was developed with the goal of improving the sensitivity and other psychometric properties of the original EQ-5D-3L [4, 5].

Janssen and colleagues, in a cross-sectional multicountry study, reported evidence of the feasibility and validity of the EQ-5D-5L in a variety of conditions, showing a low level of missing values, establishing knowngroups validity and showing improved discriminatory power and improved convergent validity in comparison with EQ-5D-3L [6]. In the context of two studied populations with stroke (from UK and from Poland), a $15 \%$ relative reduction in the ceiling was shown, as well as a valid redistribution and the highest number of different health states defined by the questionnaire, in comparison with other patients groups. Additional studies have been conducted in Germany, Italy, China, South Korea and Singapore that also support the validity of the EQ-5D-5L [7-11]. However, there is a scarcity of studies that have examined the longitudinal construct validity (i.e., responsiveness to change) of the EQ-5D-5L.

Responsiveness is the ability of an outcome instrument to detect clinically important changes within individuals with a specific condition [12]. It is evaluated in longitudinal studies of patients, in whom a change is expected to occur. In general, disease-specific instruments are more responsive than generic health status measures, as they are more focused on problems of particular importance to target patients. Although we have some knowledge about cross-sectional validity of EQ-5D-5L in stroke patients [6], we know very little about its responsiveness in stroke population.

Our objective was to evaluate the responsiveness of the EQ-5D-5L in a longitudinal study of patients with stroke. The secondary objective was to compare responsiveness of EQ-5D-5L index and other generic measures of healthrelated quality of life (HRQoL), often used in patients with stroke-EQ-5D-3L and EQ VAS.

\section{Methods}

\section{Study design}

A single-center observational longitudinal cohort study was conducted between July 2009 and May 2010. Three neurologists with experience in the use of clinical measures assessed patients with primary or recurrent stroke, at two occasions. Adult patients with primary intracerebral hemorrhage or cerebral infarction (I61 or I63 according to ICD10 classification) were included. A diagnosis had to be supported by clinical examination and computed tomography (CT) or magnetic resonance imaging (MRI). Individuals had to be Polish language native speakers. Patients in coma were excluded. In case of aphasia or dementia, the survey was administered to family members serving as a proxy.

The initial survey took place during index hospitalization, before discharge. Stroke severity was assessed with the National Institute of Health Stroke Scale (NIHSS) and the modified Rankin Scale (mRS), physical performance with the Barthel Index (BI), and HRQoL with the EQ-5D generic questionnaire (both five- and three-level versions) and the EQ-5D visual analogue scale (EQ VAS). Stroke type was classified according to Oxford Community Stroke Project (OCSP) classification into: partial anterior circulation stroke (PACS), posterior circulation stroke (POCS), lacunar stroke (LACS) or total anterior circulation stroke (TACS). The second survey was conducted after an initial post-stroke recovery phase about 4 months later, in outpatient clinics, neurological rehabilitation department or patients own home. Assessment were completed for the mRS, BI, EQ-5D-5L, EQ-5D-3L and EQ VAS using paper and pencil versions of the quality of life questionnaires.

The study conformed to the Helsinki declaration. The study protocol was approved by the local Ethics Committee, and all participants gave informed consent before inclusion.

\section{Measures}

The mRS and the BI are widely used stroke outcome measures in clinical trials and everyday practice [3]. The $\mathrm{mRS}$ is a standardized scale, with good intra-observer agreement, that evaluates the degree of disability or dependence in the daily activities of people who have suffered a stroke or neurological disability, providing a score that ranges from 0 (perfect health without symptoms) to 6 (death) [13]. BI is a valid measure of activities of daily living with a substantial body of literature describing its clinimetrics [14]. It has good reliability and reasonable responsiveness. Although sensitivity to change is limited at the extremes of disability (floor and ceiling effects), BI seems to be more sensitive than other common stroke scales [15]. We used the 10-item scale, scoring 0-100 with 5-point increments [16].

EQ-5D is a brief measure of health that has been used extensively in stroke [17]. It is available for self-completion or by proxy using paper and pencil or electronic versions (PDA, tablet and WWW). Both the EQ-5D-3L and EQ-5D-5L consist of 2 parts: a descriptive health classifier system and a visual analogue scale (EQ VAS). The EQ-5D$5 \mathrm{~L}$ descriptive system comprises the same five dimensions as the EQ-5D-3L (mobility, self-care, usual activities, pain/ 
discomfort and anxiety/depression), but has five levels of severity (no problems, slight problems, moderate problems, severe problems and extreme problems) rather than three levels (no problems, some problems and extreme problems) in EQ-5D-3L. The responses for the five dimensions can be combined in a 5-digit number describing the respondent's health state (from ' 11111 ' meaning no problems at all to ' 55555 ' meaning extreme problems in all five dimensions) [5]. A total of 243 and 3,125 possible health states are defined in this way in EQ-5D-3L and EQ-5D-5L, respectively. EQ-5D health states may be converted into a single summary index by applying a formula that attaches values (also called weights) to each of the levels in each dimension that can facilitate cost-utility analyses. To obtain EQ-5D-3L index values, we used the Polish EQ-5D$3 \mathrm{~L}$ value set derived using the time trade-off valuation technique [18] and to obtain EQ-5D-5L index scores, we used Polish interim EQ-5D-5L value set estimated using the crosswalk methodology developed by the EuroQol Group [19, 20]. The EQ VAS derives information about the

Table 1 Demographic characteristics of studied population with stroke

\begin{tabular}{|c|c|c|}
\hline & First survey & Follow-up \\
\hline$N$ & 112 & \\
\hline \multicolumn{3}{|l|}{ Age, years } \\
\hline Mean (SD) & $70.6(11.0)$ & \\
\hline Range & $39-88$ & \\
\hline Sex, F, $n(\%)$ & $58(51.8)$ & \\
\hline \multicolumn{3}{|l|}{ ICD-10, $n(\%)$} \\
\hline I61 (intracerebral hemorrhage) & $8(7.1)$ & \\
\hline I63 (cerebral infarction) & $104(92.9)$ & \\
\hline \multicolumn{3}{|l|}{ mRS, $n(\%)$} \\
\hline 0 & $2(1.8)$ & $5(4.5)$ \\
\hline 1 & $23(20.5)$ & $32(28.6)$ \\
\hline 2 & $42(37.5)$ & $42(37.5)$ \\
\hline 3 & $21(18.8)$ & $16(14.3)$ \\
\hline 4 & $14(12.5)$ & $8(7.1)$ \\
\hline 5 & $10(8.9)$ & $9(8.0)$ \\
\hline \multicolumn{3}{|l|}{ NIHSS } \\
\hline Mean (SD) & $4.1(4.8)$ & \\
\hline \multicolumn{3}{|l|}{ Assessment site, $n(\%)$} \\
\hline Hospital ward & $105(93.8)$ & $4(3.6)$ \\
\hline Outpatient clinic & $5(4.5)$ & $85(75.9)$ \\
\hline Rehabilitation ward & $2(1.8)$ & $3(2.7)$ \\
\hline Home & $0(0)$ & $20(17.9)$ \\
\hline \multicolumn{3}{|l|}{ Respondent, $n(\%)$} \\
\hline Patient & $91(81.3)$ & $102(91.1)$ \\
\hline Proxy & $21(18.7)$ & $10(8.9)$ \\
\hline
\end{tabular}

$m R S$ modified Rankin scale, NIHSS National institute of health stroke scale respondents' subjective health perception, scored on a $20-\mathrm{cm}$ visual analogue scale with endpoints labeled 'the best health you can imagine' and 'the worst health you can imagine.'

\section{Responsiveness}

Responsiveness has been defined as the ability to detect changes that are meaningful or clinically important [21]. To assess responsiveness, some criterion is needed to identify whether patients have changed (either improved or worsened) over time [22]. It is strongly recommended to use multiple independent anchors [23]. We used two external criteria (EC) based on clinical outcomes, namely $\mathrm{mRS}$ and $\mathrm{BI}$ change scores. The first criterion was based on movement between categories on the mRS at baseline and follow-up: improvement of at least one level (improvement), no movement (stable) and decline at least one level (deterioration). We made no differentiation between 'some' change and 'large' change, as there were only a small subset of patients who changed two or more levels. There are several different ways with different cut points to categorize BI outcomes [24]. Due to lack of consensus on the approach, we used the minimal clinically important difference (MCID) of the BI in stroke patients estimated by Hsiech et al. [25] of 1.85 points on a 20-point scale (or 9.25 on a 100-point scale).The BI criterion was defined as follows: improvement of at least 9.25 points (improvement), deterioration of at least 9.25 points (deterioration), deterioration of $<9.25$ points, no change or improvement of $<9.25$ points (stable).

Analysis

First, correlations between the change scores of the measures were examined using Spearman's rank correlation coefficient $\left(r_{\mathrm{s}}\right)$. The extent of correlation was interpreted as absent $(<0.20)$, poor $(0.20-0.34)$, moderate $(0.35-0.50)$ or strong $(>0.50)$ [26].

Responsiveness was evaluated using the following statistical approaches: (1) effect size, (2) standardized response mean, (3) $F$-statistic, (4) relative efficiency and (5) area under the receiver operating characteristic curve. We calculated effect size (ES) as the ratio of the mean change to the standard deviation (SD) of initial measurement, standardized response mean (SRM) as the ratio of the mean change to the SD of that change and the $F$-statistic as a squared $t$-statistic (squared ratio of the mean change to the standard error of that change). The ES construct ignores the variation in the change, and the SRM construct makes it less sensitive to sample sizes than ES [27]. Both ES and SRM were interpreted as large $(>0.8)$, moderate $(0.5-0.8)$ or small $(<0.5)[28,29]$. In analyzing test statistics, a 
Table 2 Descriptive statistics for HRQoL and clinical outcome measures

EQ VAS EQ-5D visual analogue scale, $m R S$ modified Rankin scale

\begin{tabular}{|c|c|c|c|c|c|c|}
\hline & Mean (SD) & Median (Q1-Q3) & Range & $\begin{array}{l}\% \\
\text { Floor }\end{array}$ & $\begin{array}{l}\% \\
\text { Ceiling }\end{array}$ & $\begin{array}{l}\% \\
\text { Negative }\end{array}$ \\
\hline \multicolumn{7}{|l|}{ Baseline } \\
\hline $\begin{array}{l}\text { EQ-5D-5L } \\
\text { index }\end{array}$ & $0.577(0.343)$ & $0.724(0.478-0.791)$ & $\begin{array}{c}-0.523 \text { to } \\
1.0\end{array}$ & 1.8 & 5.4 & 8.0 \\
\hline $\begin{array}{l}\text { EQ-5D-3L } \\
\text { index }\end{array}$ & $0.584(0.353)$ & $0.716(0.369-0.798)$ & $\begin{array}{c}-0.523 \text { to } \\
1.0\end{array}$ & 2.7 & 6.3 & 7.1 \\
\hline EQ VAS & $54.3(24.8)$ & $50(40-70)$ & $0-100$ & 1.8 & 3.6 & - \\
\hline Barthel index & $78.9(30.4)$ & $95(70-100)$ & $0-100$ & 2.7 & 49.1 & - \\
\hline $\mathrm{mRS}$ & $2.5(1.3)$ & $2(2-3)$ & $5-0$ & 8.9 & 1.8 & - \\
\hline \multicolumn{7}{|l|}{ Follow-up } \\
\hline $\begin{array}{l}\text { EQ-5D-5L } \\
\text { index }\end{array}$ & $0.691(0.267)$ & $0.741(0.619-0.861)$ & $\begin{array}{c}-0.231 \text { to } \\
1.0\end{array}$ & 0.0 & 7.1 & 4.5 \\
\hline $\begin{array}{l}\text { EQ-5D-3L } \\
\text { index }\end{array}$ & $0.694(0.281)$ & $0.768(0.716-0.868)$ & $\begin{array}{c}-0.523 \text { to } \\
1.0\end{array}$ & 0.9 & 9.8 & 1.8 \\
\hline EQ VAS & $60.7(22.4)$ & $60(45.5-80)$ & $0-100$ & 0.9 & 1.8 & - \\
\hline Barthel Index & $84.6(26.3)$ & $100(80-100)$ & $0-100$ & 3.6 & 55.4 & - \\
\hline $\mathrm{mRS}$ & $2.2(1.3)$ & $2(1-3)$ & $5-0$ & 8.0 & 4.5 & - \\
\hline
\end{tabular}

measure that generates the largest statistic is judged to be the most responsive. To compare the responsiveness of measures, relative efficiency (RE) was calculated by taking a ratio of $F$-statistics, where the measure with the smallest $F$-statistic served as the reference, which results in all coefficients being greater than 1 .

Receiver operating characteristic (ROC) curves were used to assess the sensitivity and specificity of different change scores [30]. We calculated the size of the area under the curve (AUROC), which corresponds to the probability of correctly identifying patients with a specified outcome according to the EC. AUROC may range from 0.5 (no discriminatory accuracy) to 1.0 (perfect accuracy) in distinguishing patients identified by this criterion [27]. We performed three groups of comparisons: improved versus stable, deteriorated versus stable and improved versus deteriorated patients.

The statistical software used was the StatsDirect 2.7.8 (StatsDirect Ltd, England). The area under the ROC was estimated by a nonparametric method analogous to the Wilcoxon/Mann-Whitney test [31]. Accompanying confidence intervals were constructed using DeLong's variance estimate [32]. All tests were two-sided. The results were considered significant at $P<0.05$.

\section{Results}

One hundred and fourteen patients were followed up for about 4 months (median 107.5 days; interquartile range (IQR) 101-123) after the initial stroke hospitalization and after a median of 98.5 days (IQR 93-111) since the first survey. Two patients were excluded from the final analysis, because of missing data: one on initial and follow-up $\mathrm{mRS}$ and one on follow-up EQ-5D-5L and EQ-5D-3L. Characteristics of the included 112 subjects are presented in Table 1 . The majority of patients had secondary (32\%) or higher $(22 \%)$ education, were retired $(71 \%)$ or pensioners $(15 \%)$, lived with their relatives $(79 \%)$ or lived independently $(20 \%)$. Comorbidities were common in the studied population: hypertension in $72 \%$ of patients, coronary artery disease in $31 \%$, diabetes in $25 \%$, atrial fibrillation in $21 \%$ and cardiac insufficiency in $16 \%$. Thirty-one percent of subjects were current smokers. The most common stroke symptoms included: upper extremity $(79 \%)$ or lower extremity paresis (64\%), dysphasia (33\%), hemianopsia $(16 \%)$, dysarthria $(31 \%)$ or brain stem or cerebral sings (15\%). In $54 \%$ and $40 \%$ of patients, stroke involved right and left side of the body, respectively, with no obvious side affected in $4 \%$. According to OCSP stroke classification, the sample was composed of: $46 \%$ PACS, $26 \%$ POCS, $20 \%$ LACS and $7 \%$ TACS. For $20 \%$ of patients, it was recurrent stroke. Median hospital stay was 10 days (IQR 8-14 days), and median intensive care unit stay was 1 day (IQR 0-2 days). Patients were discharged to their own house $(77 \%)$, rehabilitation ward $(17 \%)$ or transferred to another hospital (5\%).

Between baseline and follow-up, all clinical and HRQoL measures showed improvement based on mean and median scores (paired $t$ tests all $<0.01$; Table 2). Significant differences in the distribution of responses to self-care and usual activities EQ-5D-5L dimensions were observed (Chi-squared tests $<0.001$ and 0.001 , respectively) (Table 3).

Correlation between change scores of each measure revealed that changes in EQ-5D-5L were strongly correlated 
Table 3 Distribution of EQ-5D-5L dimension responses at baseline and at follow-up $(N=112)$

\begin{tabular}{|c|c|c|c|}
\hline Dimension & $\begin{array}{l}\text { Baseline } \\
n(\%)\end{array}$ & $\begin{array}{l}\text { Follow-up } \\
n(\%)\end{array}$ & $P$ value* \\
\hline \multicolumn{4}{|l|}{ Mobility } \\
\hline No problems & $17(15.2)$ & $34(30.4)$ & \multirow[t]{5}{*}{0.057} \\
\hline Slight problems & $28(25.0)$ & $24(21.4)$ & \\
\hline Moderate problems & $31(27.7)$ & $29(25.9)$ & \\
\hline Severe problems & $18(16.1)$ & $16(14.3)$ & \\
\hline Unable to walk about & $18(16.1)$ & $9(8.0)$ & \\
\hline \multicolumn{4}{|l|}{ Self-care } \\
\hline No problems & $28(25.0)$ & $55(49.1)$ & \multirow[t]{5}{*}{$<0.001$} \\
\hline Slight problems & $27(24.1)$ & $19(17.0)$ & \\
\hline Moderate problems & $22(19.6)$ & $18(16.1)$ & \\
\hline Severe problems & $10(8.9)$ & $12(10.7)$ & \\
\hline Unable to wash or dress & $25(22.3)$ & $8(7.1)$ & \\
\hline \multicolumn{4}{|l|}{ Usual activities } \\
\hline No problems & $16(14.3)$ & $30(26.8)$ & \multirow[t]{5}{*}{0.001} \\
\hline Slight problems & $29(25.9)$ & $27(24.1)$ & \\
\hline Moderate problems & $28(25.0)$ & $26(23.2)$ & \\
\hline Severe problems & $10(8.9)$ & $20(17.9)$ & \\
\hline $\begin{array}{l}\text { Unable to do usual } \\
\text { activities }\end{array}$ & $29(25.9)$ & $9(8.0)$ & \\
\hline \multicolumn{4}{|l|}{ Pain/discomfort } \\
\hline No pain or discomfort & $24(21.4)$ & $29(25.9)$ & \multirow[t]{5}{*}{ NS } \\
\hline Slight pain or discomfort & $26(23.2)$ & $24(21.4)$ & \\
\hline $\begin{array}{l}\text { Moderate pain or } \\
\text { discomfort }\end{array}$ & $41(36.6)$ & $40(35.7)$ & \\
\hline Severe pain or discomfort & $19(17.0)$ & $15(13.4)$ & \\
\hline $\begin{array}{l}\text { Extreme pain or } \\
\text { discomfort }\end{array}$ & $2(1.8)$ & $4(3.6)$ & \\
\hline \multicolumn{4}{|l|}{ Anxiety/depression } \\
\hline Not anxious or depressed & $20(17.9)$ & $26(23.2)$ & \multirow[t]{5}{*}{ NS } \\
\hline $\begin{array}{l}\text { Slightly anxious or } \\
\text { depressed }\end{array}$ & $36(32.1)$ & $44(39.3)$ & \\
\hline $\begin{array}{l}\text { Moderately anxious or } \\
\text { depressed }\end{array}$ & $33(29.5)$ & $31(27.7)$ & \\
\hline $\begin{array}{l}\text { Severely anxious or } \\
\text { depressed }\end{array}$ & $20(17.9)$ & $9(8.0)$ & \\
\hline $\begin{array}{l}\text { Extremely anxious or } \\
\text { depressed }\end{array}$ & $3(2.7)$ & $2(1.8)$ & \\
\hline
\end{tabular}

* Chi-square test, NS non significant

with EQ-5D-3L, moderately with EQ VAS and BI and poorly with the mRS (Table 4). EQ-5D-3L tended to have stronger levels of correlation with stroke clinical outcome measures than EQ-5D-5L. The weakest observed correlation was between EQ VAS and mRS or BI change scores. Surprisingly, the correlation between $\mathrm{mRS}$ and $\mathrm{BI}$ change scores was only moderate.

According to our predefined $\mathrm{mRS}$ external anchor, slightly more patients were defined as improved (38.4\%)
Table 4 Correlations between change scores of studied measures (Spearman's rank correlation coefficient)

\begin{tabular}{lccccc}
\hline & $\begin{array}{l}\text { EQ-5D-5L } \\
\text { index }\end{array}$ & $\begin{array}{l}\text { EQ-5D-3L } \\
\text { index }\end{array}$ & $\begin{array}{l}\text { EQ } \\
\text { VAS }\end{array}$ & $\begin{array}{l}\text { Barthel } \\
\text { Index }\end{array}$ & mRS \\
\hline $\begin{array}{c}\text { EQ-5D-5L } \\
\text { index }\end{array}$ & 1.00 & & & & \\
$\begin{array}{c}\text { EQ-5D-3L } \\
\text { index }\end{array}$ & 0.74 & 1.00 & & & \\
EQ VAS & 0.48 & 0.41 & 1.00 & & \\
$\begin{array}{l}\text { Barthel } \\
\text { index }\end{array}$ & 0.43 & 0.56 & 0.27 & 1.00 & \\
mRS & -0.31 & -0.41 & -0.32 & -0.42 & 1.00 \\
\hline EQ VAS EQ-5D visual analogue scale, $m R S$ modified Rankin scale
\end{tabular}

$E Q$ VAS EQ-5D visual analogue scale, $m R S$ modified Rankin scale

or deteriorated $(17.0 \%)$ compared with findings based on the $\mathrm{BI}$ as an external anchor $(33.0 \%$ and $13.4 \%$, respectively). Table 5 shows change scores for each measure stratified by subgroup when defined by each of the external criteria ( $\mathrm{mRS}$ and $\mathrm{BI}$ ). In general, mean EQ-5D-3L index changes were greater than mean EQ-5D-5L index changes, and the latter were greater than EQ VAS changes.

In the analysis based on external criteria, both ES and SRM are higher when patients were classified as 'improved,' rather than 'deteriorated.' In subjects who improved, indices showed at least moderate responsiveness, with responsiveness statistics associated with the EQ5D-3L index being consistently more responsive than EQ5D-5L index. In patients who improved based on the BI, both the EQ-5D-3L index and the EQ-5D-5L captured large magnitudes of effect according to the SRM. A similar pattern was observed using $\mathrm{mRS}$ as the basis for categorizing patients into outcome groups (Table 6).

Responsiveness analysis based on ROC curves similarly found that the BI worked better than mRS as an external criterion, giving higher AUROC, which indicates better accuracy. Systematically, the most responsive measure was the EQ-5D-3L index. When the external criterion was based on $\mathrm{BI}$, the second most responsive instrument was the EQ-5D-5L, but when EC was based on mRS, the second was EQ VAS (Table 7).

\section{Discussion}

In the present study, the EQ-5D-5L showed appropriate responsiveness in patients about 4 months after stroke, as confirmed by using several indices-ES, SRM, $F$-statistic, $\mathrm{RE}$ and area under the ROC curve. We noticed moderate ESs and moderate to large SRMs. Nevertheless, in our sample of stroke patients, EQ-5D-3L index appeared to be more responsive than EQ-5D-5L index scored according to 
Table 5 Descriptive statistics (mean, SD) for HRQoL and clinical outcome measures in patients classified as improved, stable or deteriorated, according to external criterion

\begin{tabular}{|c|c|c|c|c|c|c|c|}
\hline \multirow[t]{2}{*}{ Measure } & \multirow{2}{*}{$\begin{array}{l}\text { Time } \\
\text { point }\end{array}$} & \multicolumn{3}{|c|}{ mRS-based external criterion } & \multicolumn{3}{|c|}{ Barthel index-based external criterion } \\
\hline & & $\begin{array}{l}\text { Improved } \\
N=43\end{array}$ & $\begin{array}{l}\text { Stable } \\
N=50\end{array}$ & $\begin{array}{l}\text { Deteriorated } \\
N=19\end{array}$ & $\begin{array}{l}\text { Improved } \\
N=37\end{array}$ & $\begin{array}{l}\text { Stable } \\
N=60\end{array}$ & $\begin{array}{l}\text { Deteriorated } \\
N=15\end{array}$ \\
\hline \multirow{3}{*}{$\begin{array}{l}\text { EQ-5D-5L } \\
\text { index }\end{array}$} & Baseline & $0.529(0.388)$ & $0.590(0.333)$ & $0.652(0.246)$ & $0.341(0.376)$ & $0.716(0.242)$ & $0.603(0.304)$ \\
\hline & Follow-up & $0.729(0.217)$ & $0.696(0.292)$ & $0.590(0.292)$ & $0.607(0.232)$ & $0.795(0.177)$ & $0.482(0.429)$ \\
\hline & Change & $0.200(0.290)$ & $0.106(0.214)$ & $-0.061(0.247)$ & $0.267(0.311)$ & $0.078(0.165)$ & $-0.121(0.256)$ \\
\hline \multirow{3}{*}{$\begin{array}{l}\text { EQ-5D-3L } \\
\text { index }\end{array}$} & Baseline & $0.531(0.382)$ & $0.595(0.357)$ & $0.674(0.253)$ & $0.323(0.377)$ & $0.731(0.248)$ & $0.637(0.293)$ \\
\hline & Follow-up & $0.769(0.174)$ & $0.691(0.286)$ & $0.530(0.150)$ & $0.634(0.228)$ & $0.796(0.198)$ & $0.434(0.445)$ \\
\hline & Change & $0.239(0.309)$ & $0.096(0.189)$ & $-0.144(0.381)$ & $0.310(0.294)$ & $0.065(0.202)$ & $-0.203(0.352)$ \\
\hline \multirow[t]{3}{*}{ EQ VAS } & Baseline & $51.3(25.1)$ & $56.9(25.6)$ & $53.9(22.7)$ & $38.1(20.3)$ & $64.5(22.0)$ & $53.0(25.4)$ \\
\hline & Follow-up & $64.1(19.8)$ & $64.2(22.0)$ & $43.6(22.1)$ & $51.3(17.9)$ & $69.2(19.3)$ & $49.6(29.9)$ \\
\hline & Change & $12.8(21.5)$ & $7.3(20.5)$ & $-10.3(17.4)$ & $13.2(19.1)$ & $4.72(24.1)$ & $-3.4(11.2)$ \\
\hline
\end{tabular}

EQ VAS EQ-5D visual analogue scale, $m R S$ modified Rankin scale

Table 6 Responsiveness statistics for HRQoL and clinical measures by external criterion

$E Q$ VAS EQ-5D visual analogue scale, $m R S$ modified Rankin scale

\begin{tabular}{|c|c|c|c|c|c|}
\hline \multirow[t]{2}{*}{$\begin{array}{l}\text { Responsiveness } \\
\text { statistic }\end{array}$} & \multirow[t]{2}{*}{ Measure } & \multicolumn{2}{|c|}{ mRS-based external criterion } & \multicolumn{2}{|c|}{$\begin{array}{l}\text { Barthel index-based external } \\
\text { criterion }\end{array}$} \\
\hline & & $\begin{array}{l}\text { Improved } \\
N=43\end{array}$ & $\begin{array}{l}\text { Deteriorated } \\
N=19\end{array}$ & $\begin{array}{l}\text { Improved } \\
N=37\end{array}$ & $\begin{array}{l}\text { Deteriorated } \\
N=15\end{array}$ \\
\hline \multirow[t]{3}{*}{ Effect size } & $\begin{array}{l}\text { EQ-5D-5L } \\
\text { index }\end{array}$ & 0.51 & -0.25 & 0.71 & -0.40 \\
\hline & $\begin{array}{l}\text { EQ-5D-3L } \\
\text { index }\end{array}$ & 0.63 & -0.57 & 0.82 & -0.69 \\
\hline & EQ VAS & 0.51 & -0.45 & 0.65 & -0.13 \\
\hline \multirow[t]{3}{*}{$\begin{array}{l}\text { Standardized } \\
\text { response mean }\end{array}$} & $\begin{array}{l}\text { EQ-5D-5L } \\
\text { index }\end{array}$ & 0.69 & -0.25 & 0.86 & -0.47 \\
\hline & $\begin{array}{l}\text { EQ-5D-3L } \\
\text { index }\end{array}$ & 0.77 & -0.38 & 1.06 & -0.58 \\
\hline & EQ VAS & 0.59 & -0.59 & 0.69 & -0.30 \\
\hline \multirow[t]{3}{*}{$F$-statistic } & $\begin{array}{l}\text { EQ-5D-5L } \\
\text { index }\end{array}$ & 20.32 & 1.17 & 27.15 & 3.36 \\
\hline & $\begin{array}{l}\text { EQ-5D-3L } \\
\text { index }\end{array}$ & 25.68 & 2.70 & 41.30 & 4.98 \\
\hline & EQ VAS & 15.25 & 6.72 & 17.65 & 1.38 \\
\hline \multirow[t]{3}{*}{ Relative efficiency } & $\begin{array}{l}\text { EQ-5D-5L } \\
\text { index }\end{array}$ & 1.33 & 1.00 & 1.54 & 2.43 \\
\hline & $\begin{array}{l}\text { EQ-5D-3L } \\
\text { index }\end{array}$ & 1.68 & 2.31 & 2.34 & 3.60 \\
\hline & EQ VAS & 1.00 & 5.75 & 1.00 & 1.00 \\
\hline
\end{tabular}

crosswalk approach. Contrary, EQ VAS showed to function worse in the studied context.

The finding that in stroke patients EQ-5D-5L appears to be less responsive than EQ-5D-3L may be seen unexpected, as five-level version was developed with the goal of improving psychometric properties of the three-level EQ5D. It should be viewed in terms of limitations of the value set we used. An important limitation of the current study was reliance on an interim EQ-5D-5L value set derived from a crosswalk algorithm [20]. Index scores based on mapping functions are less reliable than scores from value sets based on preferences directly elicited from representative general population samples. In other study, we found that the Polish interim EQ-5D-5L value set generated values to some extent more narrow, than those generated by the EQ-5D-3L time trade-off value set. There were relatively less health states valued 'worse than death' or as a good health and, at the same time, relatively more health 
Table 7 Area under the receiver operating characteristic curve (AUROC) analysis

\begin{tabular}{llll}
\hline Compared populations & Measure & \multicolumn{1}{l}{ AUROC $(95 \%$ CI } & \\
\cline { 3 - 4 } & & External criterion: mRS & External criterion: BI \\
\hline Improved versus stable & EQ-5D-5L index & $0.57(0.45-0.69)$ & $0.71(0.59-0.83)$ \\
& EQ-5D-3L index & $0.63(0.52-0.75)$ & $0.79(0.69-0.89)$ \\
Deteriorated versus stable & EQ VAS & $0.58(0.46-0.69)$ & $0.62(0.50-0.73)$ \\
& EQ-5D-5L index & $0.70(0.44-0.95)$ & $0.70(0.41-1.00)$ \\
Improved versus deteriorated & EQ-5D-3L index & $0.74(0.45-1.00)$ & $0.75(0.43-1.00)$ \\
& EQ VAS & $0.74(0.45-1.00)$ & $0.63(0.43-0.82)$ \\
& EQ-5D-5L index & $0.75(0.62-0.89)$ & $0.83(0.72-0.94)$ \\
& EQ-5D-3L index & $0.81(0.69-0.93)$ & $0.91(0.84-0.98)$ \\
& EQ VAS & $0.80(0.69-0.92)$ & $0.75(0.62-0.88)$
\end{tabular}

$A U R O C$ area under the receiver operating characteristic curve, BI Barhel index, $m R S$ modified Rankin scale

states valued moderately [20]. Moving from 'bad health' to 'good health' resulted in a smaller change in the EQ-5D-5L index value based on crosswalk methodology than in the directly measured EQ-5D-3L index value. Although many approaches were explored by the EuroQol research team that published the crosswalk algorithm [19], it should be considered second best to direct utility measurement. At the moment, directly measured value sets for EQ-5D-5L are under development $[33,34]$. EQ-5D-5L responsiveness properties should be revisited when these sets become available.

There is no 'gold standard,' i.e., which measure is superior in establishing whether a relevant or significant change in HRQoL of stroke patients has occurred. The use of multiple clinical anchor-based criteria of change is advised. In the present study, we identified patients with improvement or worsening based on a general disability measure-mRS and a physical performance based measure-BI. It can be argued that the use of a different HRQoL measure as an anchor may give more reliable results, but both $\mathrm{mRS}$ and $\mathrm{BI}$ are recognized as the most often used standard of stroke outcome measurement [3] and were successfully used in studies of responsiveness of preference-based generic HRQoL measures in stroke [35].

Responsiveness of studied instruments was higher when external criterion was based on BI, rather than mRS. It can be that the studied indices are closely correlated with BI or that our mRS measurement had limited reliability. The $\mathrm{mRS}$ is the preferred measure of disability in stroke trials, but its value is restricted by potentially significant interobserver variability [36, 37]. Several attempts were made to reduce the bias between mRS raters, such as introduction of a structured interview, video-based training and certification, but effects have not been consistent [38]. Another explanation could be that we allowed the use of proxies, in case of aphasia or dementia. In our study, surveys performed in this way constituted less than $20 \%$ during the first survey and less than $10 \%$ at follow-up. Some authors reported that patient's assessment of HRQoL has a stronger association with mRS, while proxy responses have a stronger association with BI [39].

Contrary to other authors, we made no differentiation between some and large improvement, as there were only some patients with a shift of two or more levels in mRS [35]. We also did not exclude patients who deteriorated. Final numbers of patients with deterioration, according to mRS and BI external anchors, were low (19 and 15, respectively), posing a question about validity and generalizability of results obtained in these groups.

To our best knowledge, this is the first study of EQ-5D$5 \mathrm{~L}$ responsiveness in patients with stroke. The three-level version of EQ-5D was investigated in this context, twice. Hunger and colleagues showed reasonable validity, reliability and more limited responsiveness of a sample of German patients with a history of stroke, mild to moderate limitations of functional status, undergoing neurological rehabilitation [17]. Observed ESs were lower than estimated by Pickard et al. [35] and in our study. A possible explanation is that patients in the German study were included later after the stroke onset (median 5.7 weeks) and characterized with better functional status. As noticed by Pickard et al., the EQ-5D index is highly responsive in conditions where extreme health problems are encountered initially and subsequently improve. EQ-5D, with five dimensions and three levels, was as efficient in capturing changes as SF-6D, with six dimensions and four to six levels and Health Utility Index-3 (HUI3), with eight dimensions and five or six levels [35].

Our study is one of the first to examine the responsiveness of the EQ-5D-5L. Up till now, this topic was investigated only in women with breast cancer [11] and patients undergoing colonoscopy [40]. Swan and 
colleagues stated that EQ-5D-5L is unresponsive in colonoscopy patients, with the SRM and the ES moderately positive and a significant baseline to post-procedure change in the direction unexpected by authors. In contrast, Lee and coauthors, assessing EQ-5D-5L responsiveness in breast cancer patients, found it reasonably responsive with $\mathrm{ES}=0.52$ and 0.69 , when external criterion was based on self-assessed performance status or self-rated change in quality of life, respectively.

Future studies of the EQ-5D-5L in stroke patients should, also, provide an in-depth look at its validity and reliability, especially in the context of test-retest reliability.

We conclude that the EQ-5D-5L index, based on the crosswalk value set, seems to be appropriately responsive in patients with stroke, 4 months after disease onset. As far as EQ-5D-5L index is scored according to crosswalk approach, the EQ-5D-3L index appears to be more responsive in stroke population.

Acknowledgments This research was supported in part by the EuroQol Group.

Conflict of interest Three authors disclose that they are members of the EuroQol Group, a not-for-profit organization that develops and distributes instruments that assess and value health.

Open Access This article is distributed under the terms of the Creative Commons Attribution License which permits any use, distribution, and reproduction in any medium, provided the original author(s) and the source are credited.

\section{References}

1. Brooks, R. (1996). EuroQol: The current state of play. Health Policy, 37(1), 53-72.

2. Oemar, M., Oppe, M. (2013). EQ-5D-3L User guide. Basic information on how to use the EQ-5D-3L instrument. EuroQol Group. http://www. euroqol.org/fileadmin/user_upload/Documenten/PDF/Folders_Flyers/ EQ-5D-3L_UserGuide_2013_v5.0_October_2013.pdf. Accessed 12 April 2014.

3. Quinn, T. J., Dawson, J., Walters, M. R., \& Lees, K. R. (2009). Functional outcome measures in contemporary stroke trials. International Journal of Stroke, 4(3), 200-205. doi:10.1111/j. 1747-4949.2009.00271.x.

4. Herdman, M., Gudex, C., Lloyd, A., Janssen, M., Kind, P., Parkin, D., et al. (2011). Development and preliminary testing of the new five-level version of EQ-5D (EQ-5D-5L). Quality of Life Research, 20(10), 1727-1736. doi:10.1007/s11136-011-9903-x.

5. Oemar, M., Janssen, B. (2013). EQ-5D-5L User guide. Basic information on how to use the EQ-5D-5L instrument. EuroQol Group. http://www.euroqol.org/fileadmin/user_upload/Documenten/ PDF/Folders_Flyers/UserGuide_EQ-5D-5L_v2.0_October_2013. pdf. Accessed 12 April 2014.

6. Janssen, M. F., Pickard, A. S., Golicki, D., Gudex, C., Niewada, M., Scalone, L., et al. (2013). Measurement properties of the EQ5D-5L compared to the EQ-5D-3L across eight patient groups: a multi-country study. Quality of Life Research, 22(7), 1717-1727. doi:10.1007/s11136-012-0322-4.
7. Hinz, A., Kohlmann, T., Stobel-Richter, Y., Zenger, M., \& Brahler, E. (2014). The quality of life questionnaire EQ-5D-5L: Psychometric properties and normative values for the general German population. Quality of Life Research, 23(2), 443-447. doi:10.1007/s11136-013-0498-2.

8. Scalone, L., Ciampichini, R., Fagiuoli, S., Gardini, I., Fusco, F., Gaeta, L., et al. (2013). Comparing the performance of the standard EQ-5D 3L with the new version EQ-5D 5L in patients with chronic hepatic diseases. Quality of Life Research, 22(7), 1707-1716. doi:10.1007/s11136-012-0318-0.

9. Jia, Y. X., Cui, F. Q., Li, L., Zhang, D. L., Zhang, G. M., Wang, F. Z., et al. (2014). Comparison between the EQ-5D-5L and the EQ-5D-3L in patients with hepatitis B. Quality of Life Research,. doi:10.1007/s11136-014-0670-3.

10. Kim, S. H., Kim, H. J., Lee, S. I., \& Jo, M. W. (2012). Comparing the psychometric properties of the EQ-5D-3L and EQ-5D-5L in cancer patients in Korea. Quality of Life Research, 21(6), 1065-1073. doi:10.1007/s11136-011-0018-1.

11. Lee, C. F., Luo, N., Ng, R., Wong, N. S., Yap, Y. S., Lo, S. K., et al. (2013). Comparison of the measurement properties between a short and generic instrument, the 5-level EuroQoL Group's 5-dimension (EQ-5D-5L) questionnaire, and a longer and disease-specific instrument, the Functional Assessment of Cancer Therapy-Breast (FACT-B), in Asian breast cancer patients. Quality of Life Research, 22(7), 1745-1751. doi:10.1007/s11136012-0291-7.

12. Glossary. (2000). Health outcomes methodology. Medical Care, 38(9 Suppl II): II7-II13.

13. van Swieten, J. C., Koudstaal, P. J., Visser, M. C., Schouten, H. J., \& van Gijn, J. (1988). Interobserver agreement for the assessment of handicap in stroke patients. Stroke, 19(5), 604-607.

14. Mahoney, F. I., \& Barthel, D. W. (1965). Functional evaluation: The Barthel Index. Maryland State Medical Journal, 14, 61-65.

15. Dromerick, A. W., Edwards, D. F., \& Diringer, M. N. (2003). Sensitivity to changes in disability after stroke: A comparison of four scales useful in clinical trials. Journal of Rehabilitation Research and Development, 40(1), 1-8.

16. Quinn, T. J., Langhorne, P., \& Stott, D. J. (2011). Barthel index for stroke trials: development, properties, and application. Stroke, 42(4), 1146-1151. doi:10.1161/strokeaha.110.598540.

17. Hunger, M., Sabariego, C., Stollenwerk, B., Cieza, A., \& Leidl, R. (2012). Validity, reliability and responsiveness of the EQ-5D in German stroke patients undergoing rehabilitation. Quality of Life Research, 21(7), 1205-1216. doi:10.1007/s11136-011-00243.

18. Golicki, D., Jakubczyk, M., Niewada, M., Wrona, W., \& Busschbach, J. J. (2010). Valuation of EQ-5D health states in Poland: First TTO-based social value set in Central and Eastern Europe. Value Health, 13(2), 289-297. doi:10.1111/j.1524-4733.2009. 00596.x.

19. van Hout, B., Janssen, M. F., Feng, Y. S., Kohlmann, T., Busschbach, J., Golicki, D., et al. (2012). Interim scoring for the EQ5D-5L: Mapping the EQ-5D-5L to EQ-5D-3L value sets. Value Health, 15(5), 708-715. doi:10.1016/j.jval.2012.02.008.

20. Golicki, D., Niewada, M., van Hout, B., Janssen, M. F., \& Pickard, A. S. (2014). Interim eq-5d-51 value set for Poland: First crosswalk value set in Central and Eastern Europe. Value in Health Regional Issues, 4C, 19-23.

21. Liang, M. H. (2000). Longitudinal construct validity: Establishment of clinical meaning in patient evaluative instruments. Medical Care, 38(9 Suppl), i84-i90.

22. Revicki, D., Hays, R. D., Cella, D., \& Sloan, J. (2008). Recommended methods for determining responsiveness and minimally important differences for patient-reported outcomes. Journal of Clinical Epidemiology, 61(2), 102-109. 
23. Wyrwich, K. W., Bullinger, M., Aaronson, N., Hays, R. D., Patrick, D. L., \& Symonds, T. (2005). Estimating clinically significant differences in quality of life outcomes. Quality of Life Research, 14(2), 285-295.

24. Huybrechts, K. F., \& Caro, J. J. (2007). The Barthel Index and modified Rankin Scale as prognostic tools for long-term outcomes after stroke: A qualitative review of the literature. Current Medical Research and Opinion, 23(7), 1627-1636. doi:10.1185/ $030079907 \times 210444$.

25. Hsieh, Y. W., Wang, C. H., Wu, S. C., Chen, P. C., Sheu, C. F., \& Hsieh, C. L. (2007). Establishing the minimal clinically important difference of the Barthel Index in stroke patients. Neurorehabilation and Neural Repair, 21(3), 233-238. doi:10.1177/ 1545968306294729.

26. Juniper, E. F., Guyatt, G. H., \& Jaeschke, R. (1996). Chapter 6: How to develop and validate a new health-related quality of life instrument. In B. Spilker (Ed.), Quality of life and pharmacoeconomics in clinical trials (2nd ed., pp. 49-56). Philadelphia: Lippincott-Raven Publishers.

27. Deyo, R. A., Diehr, P., \& Patrick, D. L. (1991). Reproducibility and responsiveness of health status measures. Statistics and strategies for evaluation. Controlled Clinical Trials, 12(4 Suppl), $142 \mathrm{~s}-158 \mathrm{~s}$.

28. Cohen, J. (1988). Statistical power analysis for the behavioral sciences (2nd ed.). New Jersey: L.E. Associates.

29. Beaton, D. E., Hogg-Johnson, S., \& Bombardier, C. (1997). Evaluating changes in health status: Reliability and responsiveness of five generic health status measures in workers with musculoskeletal disorders. Journal of Clinical Epidemiology, 50(1), 79-93.

30. Deyo, R. A., \& Centor, R. M. (1986). Assessing the responsiveness of functional scales to clinical change: An analogy to diagnostic test performance. Journal of Chronic Diseases, 39(11), 897-906.

31. Hanley, J. A., \& McNeil, B. J. (1982). The meaning and use of the area under a receiver operating characteristic (ROC) curve. Radiology, 143(1), 29-36. doi:10.1148/radiology.143.1.7063747.
32. DeLong, E. R., DeLong, D. M., \& Clarke-Pearson, D. L. (1988). Comparing the areas under two or more correlated receiver operating characteristic curves: A nonparametric approach. Biometrics, 44(3), 837-845.

33. Devlin, N. J., \& Krabbe, P. F. (2013). The development of new research methods for the valuation of EQ-5D-5L. The European Journal of Health Economics, 14(Suppl 1), S1-S3. doi:10.1007/ s10198-013-0502-3.

34. Oppe, M., Devlin, N. J., van Hout, B., Krabbe, P. F., \& de Charro, F. (2014). A program of methodological research to arrive at the new international EQ-5D-5L valuation protocol. Value in Health, 17(4), 445-453. doi:10.1016/j.jval.2014.04.002.

35. Pickard, A. S., Johnson, J. A., \& Feeny, D. H. (2005). Responsiveness of generic health-related quality of life measures in stroke. Quality of Life Research, 14(1), 207-219.

36. Quinn, T. J., Dawson, J., Walters, M. R., \& Lees, K. R. (2009). Reliability of the modified Rankin Scale: A systematic review. Stroke, 40(10), 3393-3395. doi:10.1161/strokeaha.109.557256.

37. Quinn, T. J., Lees, K. R., Hardemark, H. G., Dawson, J., \& Walters, M. R. (2007). Initial experience of a digital training resource for modified Rankin scale assessment in clinical trials. Stroke, 38(8), 2257-2261. doi:10.1161/strokeaha.106.480723.

38. Wilson, J. T., Hareendran, A., Grant, M., Baird, T., Schulz, U. G., Muir, K. W., et al. (2002). Improving the assessment of outcomes in stroke: Use of a structured interview to assign grades on the modified Rankin Scale. Stroke, 33(9), 2243-2246.

39. Ali, M., Fulton, R., Quinn, T., \& Brady, M. (2013). How well do standard stroke outcome measures reflect quality of life? A retrospective analysis of clinical trial data. Stroke, 44(11), 3161-3165. doi:10.1161/strokeaha.113.001126.

40. Swan, J. S., Hur, C., Lee, P., Motazedi, T., \& Donelan, K. (2013). Responsiveness of the testing morbidities index in colonoscopy. Value Health, 16(6), 1046-1053. doi:10.1016/j.jval.2013.07.008. 